\title{
Determination of Effect of Bottle Arrangement in the Sensible Thermal Energy Storage System Consisting of Water-Filled PET Bottles on Thermal Performance
}

Dogan Erdemir (1C)

Erciyes University, Department of Mechanical Engineering, Kayseri, Turkey

\section{A BST RACT}

his study presents a theoretical investigation for determining the effect of bottle ar1 rangement on the stored energy amount in the solar heating system. 0.5-liter, 1.5-liter and 5-liter water-filled PET bottles, which are widely used in daily life, have been investigated in the terms of thermal energy storage performance. The total energy storage volume is 1,500 liters. The effects of inlet velocity, inlet temperature, bottle volume and bottle arrangement on the stored energy amount have been researched theoretically. At the end of this study, it is determined that using the water-filled PET bottles in the sensible thermal energy storage system is a practical, easy and cheap way to storing solar energy for short period storage. Additionally, since PET bottles have behaved like energy storage capsule, heat exchanger for charging and discharging processes are not required. The working fluid (air) directly circulates over PET bottles in charging and discharging periods. It is observed that decreasing bottle diameter (volume) increased the amount of thermal energy storage. The highest energy storage amount of $8,5 \mathrm{MW}$ is seen in $\mathrm{SN}=1.25 \mathrm{~d}$ and $\mathrm{SP}=2 \mathrm{~d}$ in-line arrangement. Increasing inlet velocity and inlet temperature have increased the stored energy amount.

Keywords:

Sensible thermal energy storage, Solar heating, Capsule, PET bottle

\author{
Article History: \\ Received: 2019/07/30 \\ Accepted: 2019/11/11 \\ Online: 2019/12/31
}

Correspondence to: Dogan Erdemir, Department of Mechanical Engineering, Erciyes University, 38039, Kayseri, Turkey, E-mail:erdemir@erciyes.edu.tr,

Phone: +90 $3522076666-32111$, Fax: +903524375784

\section{INTRODUCTION}

E nergy storage is a significant solution for the laE ter or cheap usage of energy, when the energy source is unavailable or expensive. The main problem related to renewable energy utilization is the time difference between the energy demand and the availability of energy sources. The most common method for solving this mismatch problem is energy storage. Thermal energy storage (TES) is a common and advanced one among the energy storage methods $[1,2]$. Basically, TES is to store the energy in a storage medium by converting the energy sources to heat. TES is divided into two sections, which are sensible and latent TES. While sensible TES is to store the energy as heat by changing the temperature of the storage medium, latent TES is to store the energy as heat by changing the phase of storage medium. TES types and storage materials are selected according to the storage capacity, environmental condition, working condition, type of energy sources, etc. Sensible TES systems are widely used in small and medium-sized solar energy cooling and heating applications. Water is a convenient storage medium because of its reasonable physical features, relatively harmless, cheapness and easy accessibility [3]. Either the water is kept as a big storage volume such as the tanks, vessels, solar ponds or in many small capsules that are held in a big storage tank. Thermal stratification is the most important issue for the thermal performance of sensible thermal energy storage tanks. Thermal stratification in sensible thermal energy storage tanks has been investigated by many researchers [4-8].

A typical TES system consists of three different processes, which are charging, storing and discharging periods. In the charging period, energy is charged to a storage medium when the energy source is active and/ or cheap. The charged energy is kept in an insulated storage container or tank with minimum loss during the 
storing period. In the discharging period, the stored energy is used when the energy source is not active and/or expensive. Thus, energy storage systems continue to provide energy, when energy sources are inactive or expensive. For example, in solar energy water and volume heating systems, energy is charged to a storage medium (water, salt, rock bed, etc.) during the daytime hours. The charged energy is stored until the time it is needed. The stored energy is then used to heat up the water or volume. Thermal energy storage (TES) is one of the most advanced and mature among energy storage types.

Kologirou [9] has investigated different solar collectors and their applications. Stinner et al. [10] have determined the performance of building which is integrated sensible TES system. Li [11] has performed the performance evaluation for sensible TES systems over the energy and exergy calculations. Navarro et al. $[12,13]$ have published two review studies related with active and passive TES systems. Caliskan et al. [14] have performed energy and exergy analyses for evaluating the system performance in building heating system which is consists thermo-chemical material and sensible TES. Anderson et al. [15] have researched the packed bed TES system. In their TES system, air is used as heat transfer fluid and alumina is used as storage medium. Cabeza and Or [16] have researched the performance of TES systems in heating and cooling applications for renewable energy sources. Dincer et al. [2] have conducted a study to determine the thermal performance for the sensible thermal energy storage systems. Tian and Zhao [17] have published a detail review study about solar collectors and thermal energy storage applications. Omu et al. [18] have developed a mixed integer programming for fascinating the design of solar domestic hot water system. Nkhonjera et al. [19] have prepared a review study about thermal energy storage designs, heat storage materials. Pintaldi et al. [20] have developed an approach for energetic evaluation of thermal energy storage options for high efficiency solar cooling systems. Ozturk [21] have performed the experimental study for investigating the daily storage of the solar energy by using the volcanic material as the sensible TES material. Rao et al. [22] have presented the theoretical investigation of heat storage characteristics and transient behavior of a sensible heat storage module of $10 \mathrm{MJ}$ storage capacity designed for discharging the heat in the high temperature range for solar power plant applications. Mulane and Havardar [23] have carried out a review study on rock bed thermal energy storage system for thermal stratification and heat extraction. Rezaie et al. [24] have modeled and analyzed the transient behavior during charging and discharging of a fully mixed open TES. Kumar et al. [25] have researched rock bed solar thermal storage system for space heating applications. Alva et al. [26] have summarized various solar thermal energy storage materials and thermal energy storage systems. The properties of solar thermal energy storage materials are discussed and analyzed.

There are many capsule shapes for TES systems. The most of these shapes are basis on cubic, cylindrical and spherical. Cylindrical and spherical capsules are widely used in the term of heat transfer characteristics. Because cylindrical and spherical capsules supply better the average heat transfer coefficient and lower pressure drop. Also Ismail and Henriquez [27] have emphasized that the plastic based material is useful for TES capsules in the terms of heat transfer and cost. The plastic-based material, such as PVC, PET etc., are widely used in TES system as capsule material, since they are enduring, easy-producing, relative harmless and cheap.

The use of water-filled PET bottles in solar thermal heating applications has been investigated by Altuntop et al. [28], Altuntop and Tekin [29] and Erdemir and Altuntop [30]. Altuntop et al. [28] have presented an analytic model for determining the performance of a sensible thermal energy storage system which is used water-filled PET bottles as a TES unit. Altuntop and Tekin [29] have presented the experimental findings for the solar energy-based floor heating system. TES unit of the system consists of the number of 5,120 1.5-liter water-filled PET bottles. At the end of their study, it has been found that the indoor sports hall can be heated by solar energy and sensible TES system. Erdemir and Altuntop [30] have performed the energy and exergy analyses in order to evaluate the solar energy heating system which is an integrated sensible TES system consists of water-filled PET bottles.

It is observed from the literature survey that using water-filled PET bottles in a sensible TES system is an easy, cheap and ready to use solution for the short period storage of solar energy. Also, there is no clear study related to determining in different working and design conditions the thermal performance of sensible TES unit which consists of water-filled PET bottles. In this study, the effects of bottle volume, bottle arrangement, inlet velocity and inlet temperature on the thermal performance of sensible TES system which is consisted of water-filled PET bottles have been researched theoretically. 0.5-liter, 1.5-liter and 5-liter PET bottles have been used in in-line and staggered arrangements. Different inlet velocity and inlet temperature have been studied. Consequently, in the present study, both the design of system and working conditions have been investigated for the sensible TES unit which consists of water-filled PET bottles. 


\section{MATERIAL AND METHODS}

\section{Details of the System and PET Bottles}

The schematic view of the solar energy heating system, which has the TES system consisted of water-filled PET bottles, is shown in Fig. 1. Solar energy heating system consists of solar collectors, fan, storage unit, water-filled PET bottles and installation equipment. The fans are used for cycling the working fluid air. Air is the working fluid in this study. This system works in three different periods.

1. The heated air in the solar collector is sent to indoor directly when the building needs heating

2. The heated air in the solar collector is sent to TES unit in order to store the solar energy when the building doesn't need heating

3. The stored energy is used, when solar energy not active and building needs heating

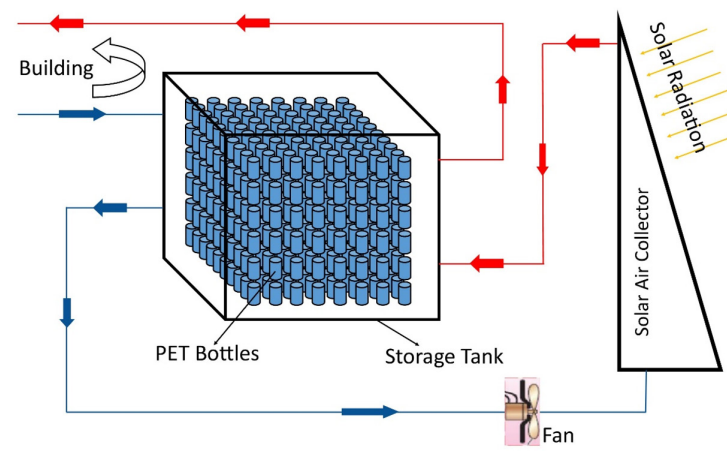

Figure 1. The schematic view of the system

In this study, 0.5-liter, 1.5-liter and 5-liter PET bottles, which are widely used in daily life, have been used as the energy storage capsule in TES system. In addition to being used as energy storage capsules, PET bottles act like heat exchangers. So, the heat exchanger for charging and discharging periods is not required in the system. Air (working fluid) circulates directly over the PET bottles. The views and dimensions of PET bottles are seen in Fig. 2. TES performance of PET bottles has been investigated by placing PET bottles in different arrangements (in-line and staggered) and positions $\left(\mathrm{S}_{\mathrm{N}}\right.$ and $\left.\mathrm{S}_{\mathrm{P}}\right)$. Also, different inlet temperatures and inlet velocities have been studied in order to determine system behavior in different working conditions. Heat transfer analyses have been performed theoretically. Some empirical equations have been applied to the system for determining the amount of stored energy. During the calculations, PET bottles have been assumed as cylinders that have a diameter $(\mathrm{d})$ and the height $(\mathrm{H})$ given, shown in Fig. 2.

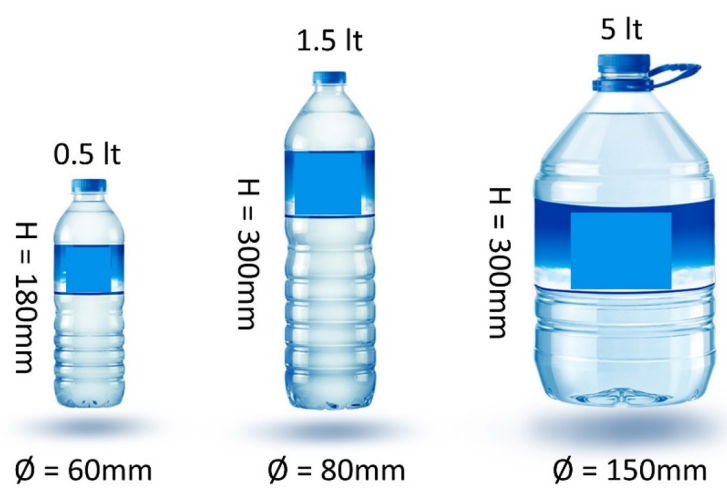

Figure 2. The views and dimensions of PET bottles

\section{Details of Storage Unit and Heat Transfer Analysis}

The schematic view of the storage unit is given in Figure 1. 0.5-liter, 1.5-liter and 5-liter PET bottles have been placed to the storage unit in in-line and staggered arrangements, respectively. The total storage volume is 1500 liters. PET bottles have been placed with $10 \times 10$ arrangement on horizontal plane. Namely, there are10 bottles in columns and rows on the horizontal plane. The bottle arrangement on the horizontal plane has been considered as constant because the arrangement on the horizontal plane had a significant effect on heat transfer analysis. So, the bottle arrangement in the horizontal plane has been taken as same for all bottle types, in order to compare in the term of heat transfer and storage performance.

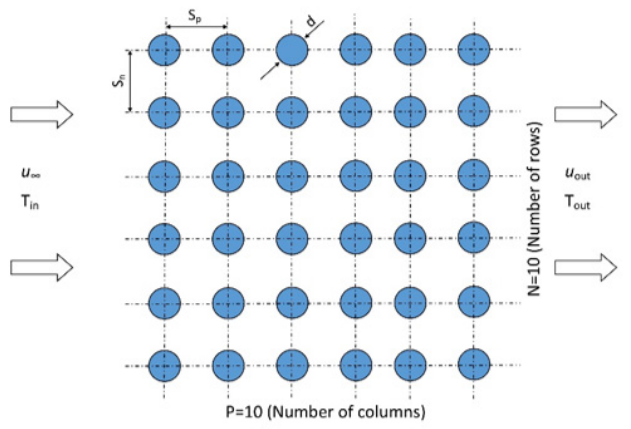

(a)

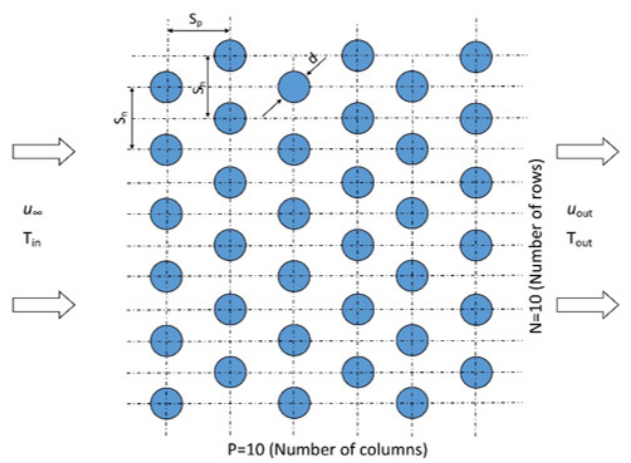

(b)

Figure 3. The arrangements of PET bottles a) in-line, b) staggered 
The number of bottles in the vertical direction has been changed for different bottle arrangements in order to set the total storage volume of 1500 liters. In the present study, there are 30 arrays for 0.5 -liter bottle, 10 arrays for 1.5 -liter and 3 arrays for 5 -liter in the vertical plane. Total numbers of 0.5-liter bottles are 3000 pieces, 1.5-liter bottles are 300 pieces and 5-liter bottles are 300 pieces. The arrangements in the horizontal plane of PET bottles are seen in Fig. 3. PET bottles have been placed in two different arrangements in the horizontal plane. These are in-line (Fig. 3.a) and staggered (Fig. 3.b). The distance between the bottles has been taken as $1.25 \mathrm{~d}, 1.50 \mathrm{~d}$ and $2.00 \mathrm{~d}$ in rows and columns. It is considered that there is no distance between the bottles in the vertical direction. Besides the bottle arrangement, the effects of air inlet velocity and inlet temperature on TES performance have investigated.

Heat transfer analysis for heated air flow across the PET bottles array has been calculated by equations, which is presented by Grimson [31] and situated in Holman [32]. The average heat transfer coefficient in tube banks (PET bottles) can be calculated as follows:

$$
N u_{(d, f)}=\frac{h d}{k_{f}}=C \operatorname{Re}_{d}^{n} \operatorname{Pr}_{f}^{1 / 3}
$$

where $\mathrm{C}$ and $\mathrm{n}$ are constant coefficients taken from the table which is situated in [32]. During the flow across the tube bank, the maximum velocity in tube banks $u_{\max }$ must be calculated for determining the maximum Reynolds number $\operatorname{Re}_{\mathrm{d}, \max } \cdot \mathrm{u}_{\max }$ for in-line and staggered arrangements are given below, respectively:

$$
\begin{aligned}
& u_{\max }=u_{\infty}\left(S_{n} /\left(S_{n}-d\right)\right) \\
& u_{\max }=\frac{u_{\infty}\left(S_{n} / 2\right)}{\left(\left(S_{n} / 2\right)^{2}+S_{p}^{2}\right)^{1 / 2}-d}
\end{aligned}
$$

After calculating $\mathrm{u}_{\max }$, the maximum Reynolds number $\left(\operatorname{Re}_{\mathrm{d} \text {,max }}\right)$ can been calculated by Eq.4.

$$
\operatorname{Re}_{d, \max }=\frac{\rho_{f} u_{\text {max }} d}{\mu_{f}}
$$

The average heat transfer coefficient can be calculated by writing $\mathrm{Re}_{\mathrm{d} \text { max }}$ in Eq.1. The working fluid has been assumed as incompressible. Physical properties of the fluid have been taken as depended on temperature. Also, heat loss has not been taken into consideration. Stored energy amount can be defined as below:

$$
\dot{Q}_{\text {stored }}=A_{t, \text { sur }}\left(T_{\text {sur }}-T_{\text {bulk }}\right)
$$

where $\mathrm{T}_{\text {sur }}$ is the surface temperature of PET bottles and $\mathrm{T}_{\text {bulk }}$ is the bulk fluid temperature. Also, stored energy amount, $\dot{Q}_{\text {stored }}$ is equal to charged energy amount $\dot{Q}_{\text {charged }}$ given in Eq.6.

$$
\dot{Q}_{\text {charged }}=\dot{m} c_{p, f}\left(T_{i n}-T_{\text {out }}\right)
$$

The outlet temperature of air from storage unit can be calculated by considering $T_{\text {bulk }}=\left(T_{\text {in }}-T_{\text {out }}\right) / 2$ and $\dot{Q}_{\text {charged }}=\dot{Q}_{\text {stored }}$. Also, $\mathrm{T}_{\text {sur }}$ can be taken as water temperature inside the bottle.

\section{RESULTS AND DISCUSSION}

In this study, the amount of the stored heat in the water filled PET bottles has been investigated theoretically. PET bottles have been placed to a storage tank in in-line and staggered arrangements, respectively. The distances in columns and rows between the PET bottles have been taken as $1.25 \mathrm{~d}, 1.50 \mathrm{~d}$ and $2.00 \mathrm{~d}$. Additionally, the effect of inlet temperature and inlet velocity on thermal energy storage performance have been researched. The parameters used in the present work are summarized in Table 1. As seen from Table 1, 2700 different cases have been investigated. A program code has been developed by using MATLAB 2015a in order to analyze heat transfer in the storage unit. The effect of parameters given in Table 1 on the amount of stored energy has been calculated with this code.

Table 1. Studied parameters

\begin{tabular}{cc}
\hline Parameter & Value \\
\hline Bottle volume, liter & $0.5,1.5,5$ \\
Arrangements & in-line, staggered \\
$S_{N}$ & $1.25 d, 1.5 d, 2 d$ \\
$S_{P}$ & $1.25 d, 1.5 d, 2 d$ \\
Inlet velocity, $U_{\infty}, \mathrm{m} / \mathrm{s}$ & $0.5,1,1.5, \ldots, 9,9.5,10$ \\
Inlet temperature, $T_{i n}{ }^{\circ} \mathrm{C}$ & $50,70,80,90$ \\
\hline
\end{tabular}

\section{The Influence of Bottle Volume and Dimensions}

0.5-liter, 1.5-liter and 5-liter PET bottles, which are widely used in daily life, have been used in the present study. Because the arrangement and number of bottles in horizontal plane are significant effect on heat transfer in the storage unit, PET bottles have been placed to horizontal plane in $10 \times 10$ arrangement. 1500 liters of the total storage volume has been considered. So, the number of bottles in the vertical plane is different. The number of bottles in the vertical plane has not important effect on the heat transfer analysis. Also, it has been considered that there is no distance between the PET bottles in the vertical position. The effect of PET bottle volumes on the stored energy amount $\left(Q_{\text {stored }}\right)$ for different 12 cases are seen in Fig. 4. As seen from Fig. 4, the stored energy amount has decreased with the increasing bottle volume, because the diameter of bottle increases with increasing bottle volume. So, the maximum Reynolds number has increased with increasing bottle diameter. Higher Reynolds number has caused the higher Nusselt number and average heat transfer coefficient. Although the average 


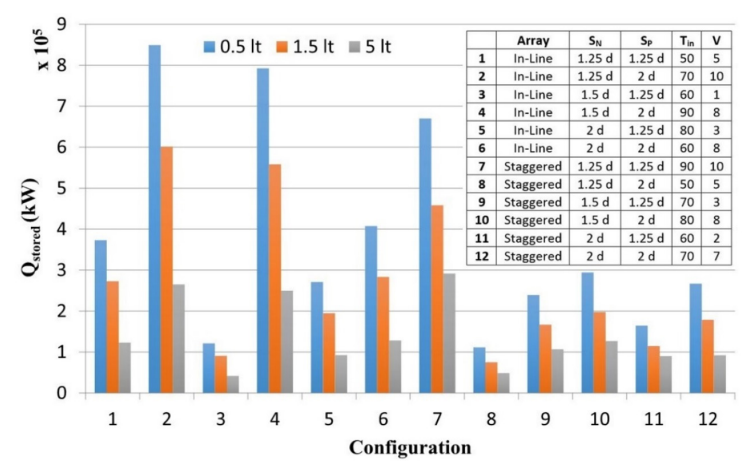

Figure 4. The effect of PET bottle volume on the stored energy amount

heat transfer coefficient has increased with increasing bottle diameter, the stored energy amount has decreased. Because, the total heat transfer surface area for the bottles has decreased with the increasing bottle diameter.

\section{The Influences of Air Inlet Velocity and Temperature}

The stored energy amount changing with the inlet velocity is seen in Fig. 5 for the case, which is $\mathrm{S}_{\mathrm{N}}=1.25 \mathrm{~d}$, $\mathrm{S}_{\mathrm{P}}=1.25 \mathrm{~d}$ and $\mathrm{T}_{\text {in }}=70{ }^{\circ} \mathrm{C}$ for 5 -liter bottle. The treatment seen in Fig. 5 is same for the all cases. $\operatorname{Re}_{\mathrm{d} \text {,max }}, \mathrm{Q}_{\text {stored }}, \mathrm{Nu}$ and $h$ have increased with increasing inlet velocity. Because, the turbulent effect in storage unit has increased with increased inlet velocity. So, the stored energy amount has increased with increasing inlet velocity.

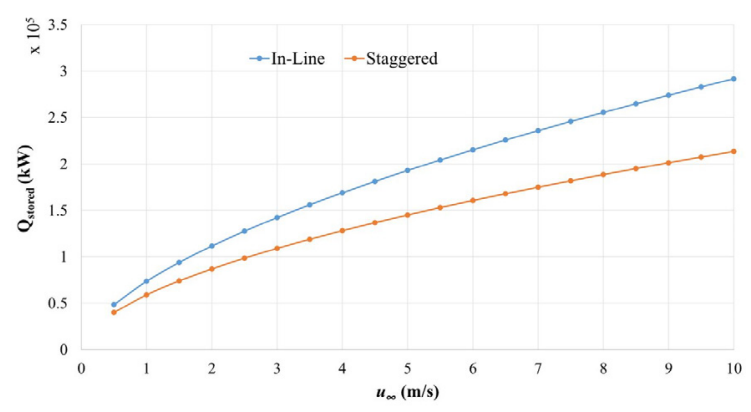

Figure 5. The effect of inlet velocity on the thermal performance of sensible TES

The effect of air inlet temperature on the stored energy amount, $\mathrm{Q}_{\text {stored }}$ is seen in Fig. 6. Different five cases are given in Fig. 6. All cases in the present study have showed same behavior with the five cases seen in Fig. 6 . As can be seen from Fig. 6, the stored energy amount has increased with higher inlet temperature. Because higher inlet temperature has caused to higher temperature difference between the bottle surface and the bulk temperature. Besides that, the rate of increase of $\mathrm{Q}_{\text {stored }}$ is not same with the temperature increasing rate. While the inlet temperature has increased from 50 to $90^{\circ} \mathrm{C}, \mathrm{Q}_{\text {stored }}$ increased $27,21,17,14 \%$.

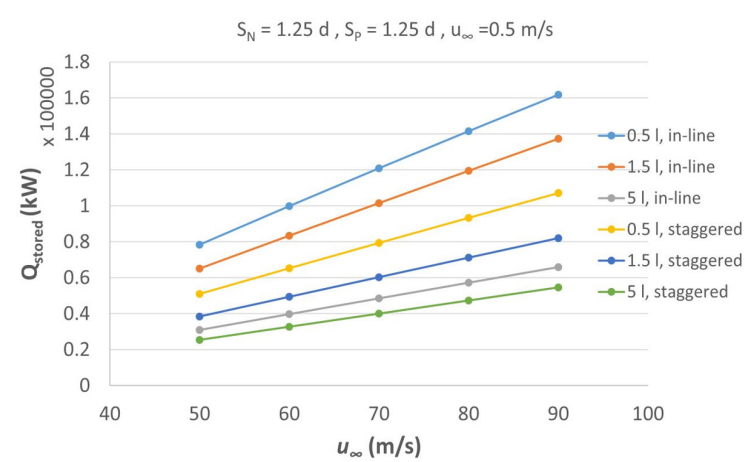

Figure 6. The effect of inlet temperature on the thermal performance of sensible TES

\section{The Influence of PET Bottle Arrangement}

Flow over the PET bottles located in the first row is similar the flow over the single PET bottle. When downstream rows are considered, flow conditions depend strongly on the PET bottle arrangement. In in-line arrangement, the pipes stayed back side of the first row are under the higher turbulent affect. With the decreasing $\mathrm{S}_{\mathrm{p}}$, the heat convection coefficient increases due to turbulence effects. In general, the overall heat transfer coefficient for a row increases up to fifth row. After fifth row, significant changing in heat transfer characteristic does not occur depending on flow conditioning. In staggered arrangement, the path of main flow is more complicated than in-line arrangement, so turbulence affects in storage unit is higher. Generally, in low Reynolds numbers $\left(\operatorname{Re}_{\mathrm{D}}<100\right)$ the overall heat transfer coefficient in staggered arrangement is higher than in-line arrangement. However, the difference in overall heat transfer coefficient between in-line and staggered arrangements decreases with the increasing Reynolds number. The difference in the heat transfer characteristics for the PET bottle arrangements is based on $\mathrm{u}_{\max }$ and $\mathrm{Re}_{\mathrm{d} \text {,max }}$. These values change with the arrangements. As can be seen from Fig. 5, in-line arrangement shows better heat transfer performance in the same inlet velocity. In the present study, the air inlet velocity has been taken as input parameter. Although the air inlet velocity has been taken same, maximum air velocity in the storage unit and also Reynolds number has changed with the PET bottle arrangement. So, the maximum Reynolds number $\left(\operatorname{Re}_{\mathrm{d} \text {,max }}\right)$ has been used for comparing the arrangements of PET bottles.

The stored energy amount changing with $\left(\operatorname{Re}_{\mathrm{d}, \max }\right)$ in in-line and staggered arrangements is seen in Fig. 7 for the case which is $\mathrm{S}_{\mathrm{N}}=1.25 \mathrm{~d}, \mathrm{~S}_{\mathrm{P}}=1.25 \mathrm{~d}, \mathrm{~T}_{\text {in }}=70^{\circ} \mathrm{C}$ for 5 -liter PET bottle (the same case with Fig. 5). As can be seen from Fig. 7 there is no significant difference between in-line and staggered arrangements in the terms of heat transfer characteristic and the stored energy amount. Because Reynolds num- 
ber is high in this study. As emphasized before, the overall heat transfer coefficient has affected from the arrangements in low Reynolds number $\left(\operatorname{Re}_{\mathrm{D}}<100\right)$. All cases studied in the present study showed similar behavior with the case given in Fig. 7.

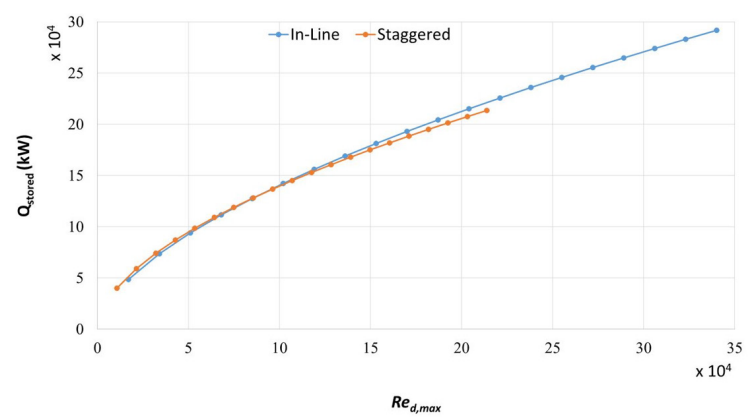

Figure 7. The effect of PET bottle arrangements on the thermal performance of sensible TES

\section{The Influences of $S_{\mathrm{P}}$ and $S_{\mathrm{N}}$ Distances between PET Bottles}

In this study, the effects of distances between the PET bottles, which are vertical to flow direction $\left(\mathrm{S}_{\mathrm{N}}\right)$ and parallel to flow direction $\left(S_{\mathrm{P}}\right)$, on the stored energy amount have been investigated. $S_{N}$ and $S_{P}$ have been taken as $1.25 \mathrm{~d}, 1.50 \mathrm{~d}$ and $2.00 \mathrm{~d}$. The stored energy amount $Q_{\text {stored }}$ changing with $\mathrm{S}_{\mathrm{N}}$ and $\mathrm{S}_{\mathrm{p}}$ for in-line and staggered arrangements are seen in Fig. 8 and Fig. 9, respectively. The selected case for Fig. 8 and Fig. 9 is $\mathrm{u}_{\infty}=5 \mathrm{~m} / \mathrm{s}, \mathrm{T}_{\text {in }}=90^{\circ} \mathrm{C}$ and 0.5-liter PET bottle. The effects of $S_{N}$ and $S_{p}$ on the thermal performance are same with this selected case. As can be seen from $\mathrm{S}_{\mathrm{N}}$ Fig. 8, in in-line arrangement, the stored energy amount has decreased substantially with the increasing $\mathrm{S}_{\mathrm{N}}$. Because, the turbulent effect has decreased with the increasing $S_{N}$ distance, the heat transfer between air and water filled PET bottles also has decreased. Therefore, closer PET bottle placement in the direction vertical to flow direction has increased the stored energy amount. The effect of $S_{p}$ on thermal energy storage performance is also seen in Fig. 9 for in-line arrangement. There is no significant effect of $S_{p}$ on the thermal performance of system in the same $S_{N}$. When $S_{N}$ increases from $1.25 \mathrm{~d}$ to $1.50 \mathrm{~d}, \mathrm{Q}_{\text {stored }}$ has reduced a small amount. After $1.50 \mathrm{~d}, \mathrm{Q}_{\text {stored }}$ has increased a small amount. When all results considered for in-line arrangement, the lower $\mathrm{S}_{\mathrm{N}}$ and lower $\mathrm{S}_{\mathrm{P}}$ have supplied higher stored heat amount. The effects of $S_{N}$ and $S_{p}$ for the staggered arrangement on the system performance is seen in Fig. 9. In the staggered arrangement, in contrast with in-line arrangement, $\mathrm{Q}_{\text {stored }}$ has increased with increasing $\mathrm{S}_{\mathrm{N}}$. Because the turbulent effects has increased with increasing $\mathrm{S}_{\mathrm{N}}$ in storage unit. Consequently, Nusselt number and the overall heat transfer coefficient have increased with the increasing $\mathrm{S}_{\mathrm{N}}$. Additionally, the stored heat decreased with the increasing $S_{\mathrm{p}}$, since the turbulent effects have decreased. Con- sequently, in order to supply higher stored heat amount in staggered arrangement, $\mathrm{S}_{\mathrm{N}}$ should be higher, and $\mathrm{S}_{\mathrm{P}}$ should be lower.

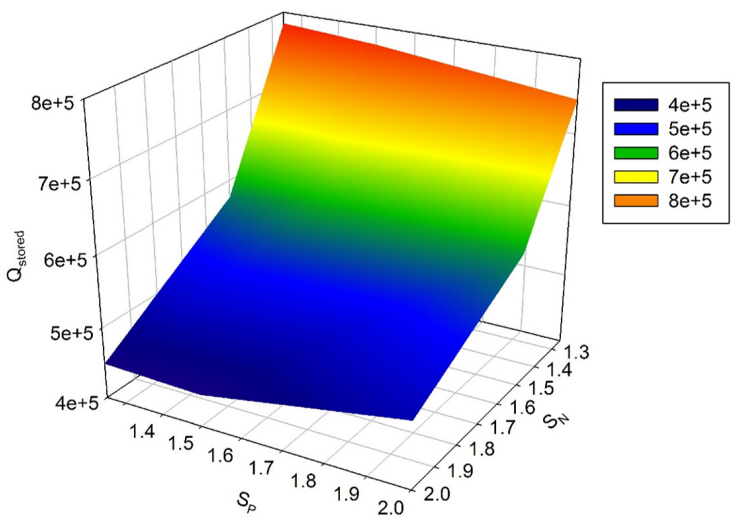

Figure 8. The effects of $S_{N}$ and $S_{p}$ on the amount of stored heat for the in-line arrangement

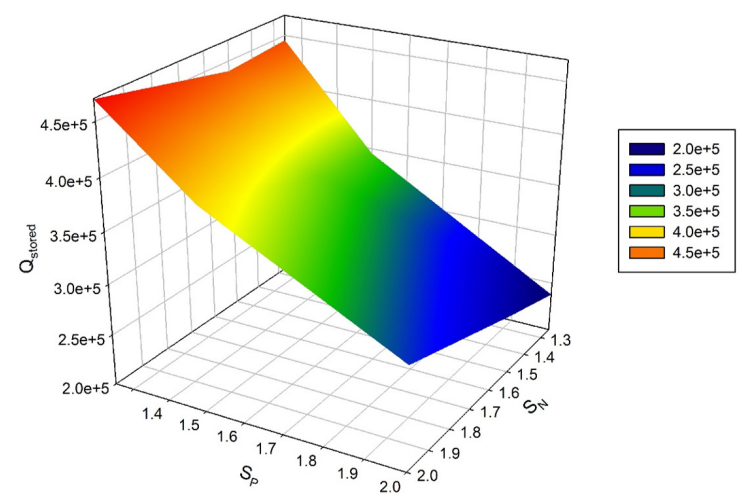

Figure 9. The effects of $\mathrm{S}_{\mathrm{N}}$ and $\mathrm{S}_{\mathrm{p}}$ on the amount of stored heat for the staggered arrangement

\section{CONCLUSION}

This study presents a determination of the effect of bottle arrangements on sensible thermal energy storage for the storage unit which is consisted of water-filled PET bottles. Also, different PET bottle volumes, which are widely used in daily life, 0.5-liter, 1.5-liter and 5-liter are studied. The effect of operating conditions which are inlet temperature and inlet velocity also researched. The total volume of the storage unit is 1500 liters. PET bottles are easy-produced, cheap and recycling materials. Also, they are ready to use. In the present study, the availability of PET bottles using as a thermal energy storage capsule has been investigated theoretically in solar heating system applications. Previous studies have shown that water-filled PET bottles are suitable for low temperature sensible thermal energy storage capsule. The heat exchangers for the collector and building cycles are not required when PET bottles (capsules) have been used in the thermal energy storage unit. In order to supply higher the amount of stored heat, lower volume water-filled PET bottles should be used in the system. There is no significant 
difference between in-line and staggered arrangements in terms of the stored energy amount in the higher Reynolds number. Additionally, while lower $S_{N}$ and $S_{p}$ should be preferred in the in-line arrangement, higher $S_{N}$ and lower $S_{p}$ should be used in the staggered arrangement. The amount of highest stored energy of 8,5 MW is seen in $\mathrm{S}_{\mathrm{N}}=1.25 \mathrm{~d}$ and $\mathrm{S}_{\mathrm{P}}=2 \mathrm{~d}$ in-line arrangement. Ultimately, it has been observed that using water-filled PET bottles as a sensible thermal energy storage capsule is an easy, cheap, ready to use and high-performance solution.

\section{NOMENCLATURE}

\begin{tabular}{|c|c|}
\hline \multicolumn{2}{|c|}{ Abbreviations } \\
\hline TES & Thermal energy storage \\
\hline PET & Polyethylene terephthalate \\
\hline \multicolumn{2}{|l|}{ Symbols } \\
\hline$A_{t, \text { sur }}$ & Total surface area of PET bottles $\left(\mathrm{m}^{2}\right)$ \\
\hline$c_{p, f}$ & Specific heat for fluid (kJ/kg K) \\
\hline$d$ & The diameter of the PET bottle (m) \\
\hline $\mathrm{h}$ & Heat transfer coefficient $\left(\mathrm{W} / \mathrm{m}^{2} \mathrm{~K}\right)$ \\
\hline $\mathrm{H}$ & The height of the PET bottle (m) \\
\hline $\mathrm{k}_{\mathrm{f}}$ & Heat conduction coefficient for fluid \\
\hline $\mathrm{N}$ & Number of rows \\
\hline \multicolumn{2}{|c|}{$\mathrm{Nu}_{\mathrm{d}, \mathrm{f}}$ Nusselt number } \\
\hline $\mathrm{P}$ & Number of columns \\
\hline $\operatorname{Pr}$ & Prandtl number \\
\hline$\dot{Q}_{\text {stored }}$ & The amount of the stored energy (W) \\
\hline$\dot{Q}_{\text {charged }}$ & The amount of the stored energy (W) \\
\hline $\operatorname{Re}$ & Reynolds number \\
\hline $\begin{array}{c}\mathrm{S}_{\mathrm{P}} \\
\text { tion }(\mathrm{m})\end{array}$ & The distance parallel to the flow direc- \\
\hline $\begin{array}{c}\mathrm{S}_{\mathrm{N}} \\
\operatorname{tion}(\mathrm{m})\end{array}$ & The distance normal to the flow direc- \\
\hline $\mathrm{T}_{\text {bulk }}$ & Bulk temperature $\left({ }^{\circ} \mathrm{C}\right)$ \\
\hline $\mathrm{T}_{\text {out }}$ & Outlet temperature $\left({ }^{\circ} \mathrm{C}\right)$ \\
\hline $\mathrm{T}_{\text {sur }}$ & Surface temperature $\left({ }^{\circ} \mathrm{C}\right)$ \\
\hline $\mathrm{T}_{\text {in }}$ & Inlet temperature $\left({ }^{\circ} \mathrm{C}\right)$ \\
\hline$(\mathrm{m} / \mathrm{s})^{\mathrm{u}_{\max }}$ & Maximum velocity in the tube bank \\
\hline $\mathrm{u}_{\infty}$ & Inlet velocity $(\mathrm{m} / \mathrm{s})$ \\
\hline $\mathrm{u}_{\mathrm{out}}$ & Outlet velocity (m/s) \\
\hline
\end{tabular}

Greek Letter

$\begin{array}{ll}\varnothing & \text { The diameter of the PET bottle } \\ \rho_{\mathrm{f}} & \text { The density of the working fluid } \\ \mu_{\mathrm{f}} & \text { The viscosity of the working fluid }\end{array}$

\section{References}

1. Acar C. A comprehensive evaluation of energy storage options for better sustainability. International Journal of Energy Research 42 (2018) 3732-3746.

2. Dincer I, Dost S, and Li X. Performance analyses of sensible heat storage systems for thermal applications. International Journal of Energy Research 21, 12 (1997) 1157-1171.

3. Dincer I, Rosen MA. Thermal Energy Storage Systems and Applications, first ed. John Wiley and Sons, West Sussex, UK.

4. Arslan M. Igci AA. Thermal performance of a vertical solar hot water storage tank with a mantle heat exchanger depending on the discharging operation parameters. Solar Energy 116 (2015) 184-204.

5. Dragsted J, Furbo S, Dannemand M, Bava D. Thermal stratification built up in hot water tank with different inlet stratifiers. Solar Energy 147 (2017) 414-425.

6. Erdemir D. Altuntop N. Improved thermal stratification with obstacles placed inside the vertical mantled hot water tanks. Applied Thermal Engineering 100 (2016) 20-29.

7. Rosen MA. The exergy of stratified thermal energy storages. Solar Energy 71,3 (2001) 173-185.

8. Rosen MA. Tang R. Dincer I. Effect of stratification on energy and exergy capacities in thermal storage systems. International Journal of Energy Research 28,2 (2004) 177193.

9. Kalogirou SA. Solar thermal collectors and applications. Progress in Energy and Combustion Science, 30,3 (2004) 231-295.

10. Stinner S. Huchtemann K. Müller D. Quantifying the operational flexibility of building energy systems with thermal energy storages. Applied Energy 191 (2016) 140154.

11. Li G. Sensible heat thermal storage energy and exergy performance evaluations. Renewable and Sustainable Energy Reviews 53 (2016) 897-923.

12. Navarro L. de Garcia A. Colclough S. Browne M. McCormack SJ. Griffiths P. Cabeza LF. Thermal energy storage in building integrated thermal systems: A review. Part 1. active storage systems. Renewable Energy 88 (2016) 526-547.

13. Navarro L. de Garcia A. Niall D. Castell A. Browne M. McCormack SJ. Griffiths P. Cabeza LF. Thermal energy storage in building integrated thermal systems: A review. Part 2. Integration as passive system. Renewable Energy 85 (2016) 1334-1356.

14. Caliskan H. Dincer I. Hepbasli A. Energy and exergy analyses of combined thermochemical and sensible thermal energy storage systems for building heating applications. Energy and Buildings 48 (2012) 103-111.

15. Anderson R. Bates L. Johnson E. Morris JF. Packed bed thermal energy storage: A simplified experimentally validated model. Journal of Energy Storage, 4 (2015) 14-23.

16. Cabeza LF. Oró E. 7 - Thermal energy storage for renewable heating and cooling systems, in Renewable Heating and Cooling, (2016) Woodhead Publishing. 139-179.

17. Tian Y. Zhao CY. A review of solar collectors and thermal energy storage in solar thermal applications. Applied Energy 104 (2013) 538-553.

18. Omu A. Hsieh S. Orehounig K. Mixed integer linear programming for the design of solar thermal energy systems with short-term storage. Applied Energy, 180 (2016) 313316 
19. Nkhonjera L. Bello-Ochende T. John G. King'ondu CK. A review of thermal energy storage designs, heat storage materials and cooking performance of solar cookers with heat storage. Renewable and Sustainable Energy Reviews 75 (2017) 157-167.

20. Pintaldi S. Sethuvenkatraman S. White S. Rosengarten G. Energetic evaluation of thermal energy storage options for high efficiency solar cooling systems. Applied Energy 188 (2017) 160-177.

21. Ozturk HH. Comparison of energy and exergy efficiencies of an underground solar thermal storage system. International Journal of Energy Research, 28,4 (2004) 341-353.

22. Rao CRC. Niyas H. Prasad L. Palanisamy M. Performance Investigation of Lab-Scale Sensible Heat Storage System (2018) Springer, Singapore. 169-186.

23. Mulane SA. Havaldar SN. A Review on Rock Bed Thermal Energy Storage System for Thermal Stratification and Heat Extraction. International Journal of Current Engineering and Technology 7 (2017) 335-337.

24. Rezaie B. Reddy BV. Rosen MA. Thermodynamic analysis and the design of sensible thermal energy storages. International Journal of Energy Research 41,1 (2017) 3948.

25. Kumar A. Buddhi D. Yadav SK. Reddy SBK. Studies of Rock Bed Solar Thermal Storage System for Space Heating
Applications. Emerging Trends in Science and Technology 3,11 (2016) 4764-4770.

26. Alva G. Liu L. Huang X. Fang G. Thermal energy storage materials and systems for solar energy applications. Renewable and Sustainable Energy Reviews 68 (2017) 693706.

27. Ismail KAR. Henriquez JR. Numerical and experimental study of spherical capsules packed bed latent heat storage system. Applied Thermal Engineering 22,5 (2002) 17051716.

28. Altuntop N. Tekin Y. Demiral D. Analytical investigation of the use of water filled P.E.T. bottles as thermal energy storage unit. Paper presented at 4th International Thermal Energy Congress.

29. Altuntop N. Tekin Y. The first performance results of the solar heating and thermal energy storage by using P.E.T. bottles. Paper presented at European solar Congress (EUROSUN 2002).

30. Erdemir D. Altuntop N. Thermodynamic analysis of sensible thermal energy storage in water filled PET bottles. International Journal of Exergy 26,1-2 (2018) 77-92.

31. Grimson ED. Correlation and Utilization of New Data on Flow Resistance and Heat Transfer for Cross Flow of Gases over Tube Banks. Trans. ASME 59 (1937) 583-594.

32. Holman JP. Heat Transfer (2014) McGraw-Hill, Newyork. 